\title{
Impacto de la pandemia de Covid-19 en el consumo de medios en España
}

\section{Impact of the Covid-19 pandemic on media consumption in Spain}

Mireia Montaña Blasco. Universitat Oberta de Catalunya. España.

mmontanabl@uoc.edu

$[\mathrm{CV}] \mathrm{C} \mathrm{G}$

Candela Ollé Castellà. Universitat Oberta de Catalunya. España.

collec@uoc.edu

$[\mathrm{CV}] \mathrm{C}$

Montse Lavilla Raso. Universitat Oberta de Catalunya. Havas Media. España.

mlavilla@uoc.edu

[CV]

Agradecimiento

Havas Media por facilitarnos los datos resultantes de la encuesta.

Cómo citar este artículo / Referencia normalizada

Montaña Blasco, M.; Ollé Castellà, C. y Lavilla Raso, M. (2020). Impacto de la pandemia de Covid-19 en el consumo de medios en España. Revista Latina de Comunicación Social, 78, 155-167. https://www.doi.org/10.4185/RLCS-2020-1472

\section{RESUMEN}

Introducción: Este estudio tiene como objetivo explorar el impacto de la pandemia de Covid-19 en los hábitos y el consumo de medios en España, uno de los países más gravemente afectados. Metodología: Se realizó una encuesta en línea representativa de la población española $(\mathrm{N}=1,500$ participantes) del 13 al 30 de marzo del 2020, coincidiendo con las primeras semanas de confinamiento en el hogar. La muestra se estudió según dos variables, género (mujeres $\mathrm{N}=750$; hombres $\mathrm{N}=750)$ y edad $(18-39$ años $\mathrm{N}=720$ y más de 40 años $\mathrm{N}=780)$ para detectar las especificidades más relevantes de cada colectivo. El error muestral es del $\pm 4,38 \%$ al $95 \%$ de confianza. Resultados: La televisión destaca como el medio más utilizado a la hora de informarse sobre el virus, por delante de los medios digitales. Cabe destacar también que programas televisivos tipo "infoshows" consiguen acumular más audiencia que los informativos tradicionales. Los medios menos utilizados para informarse sobre la evolución del Covid-19 serían internet, redes sociales, radio, información proporcionada por familiares o conocidos y prensa en papel. Aunque no destaca el consumo de la radio para mantenerse informado, este medio es considerado como el más creíble, conjuntamente con la televisión. Por último, el consumo de las plataformas "over-the-top" (OTT) ha crecido de forma considerable durante este periodo. Discusión y conclusiones: La televisión recupera así la audiencia de los más jóvenes que parecía haber perdido a favor de los medios digitales, consolidando un panorama mediático cada vez más complejo y competitivo.

PALABRAS CLAVE: audiencias; consumo de medios; hábitos; crisis sanitarias; Coronavirus; COVID-19; confinamiento. 


\begin{abstract}
Introduction: This study aims to explore the impact of the Covid-19 pandemic on media habits and consumption in Spain, one of the most severely affected countries. Methodology: A representative online survey of the Spanish population ( $N=1,500$ participants) was conducted from March 13 to 30,2020 , coinciding with the first weeks of home confinement. The sample was studied according to two variables, gender (Women $\mathrm{N}=750$; Men $\mathrm{N}=750$ ) and age (18-39 years individuals, $\mathrm{N}=720$; over 40 years individuals $\mathrm{N}=780$ ) to detect the most relevant specificities of each group. The sampling error is $\pm 4.38 \%$ to $95 \%$ confidence. Results: Results highlight that television is the most used media when it comes to finding out about the virus, before digital media. It should be noted that infoshow-type television programs manage to accumulate more audience than the traditional news programs. The least used media to get information about the evolution of the Covid-19 are Internet, social networks, radio, information by relatives or acquaintances, and traditional press. Although radio consumption seems not to be significant to stay informed, this medium is the most credible, in addition to television. Finally, the consumption of over-the-top (OTT) platforms has grown considerably during this period. Discussion: Television recovers the audience of the youngest targets that it seemed to have lost in in favor of digital media. Conclusions: An increasingly complex and competitive media landscape is consolidating.
\end{abstract}

KEYWORDS: audiences; media consumption; habits; crisis situations; health crises; Coronavirus; COVID-19; confinement.

\title{
CONTENIDO
}

1. Introducción. 2. Metodología. 3. Resultados. 4. Discusión y conclusiones. 5. Bibliografía.

6. Currículum Vitae

\section{Introducción}

La irrupción de Covid-19 en diciembre de 2019 en China se ha convertido en una crisis de salud a nivel global, que afecta a más de 185 países de los cinco continentes, y que en España ha causada hasta el momento más de 27.000 fallecidos y más de 140.000 recuperados.

El estado de alarma decretado por el gobierno español empezó el 14 de marzo (Real decreto 463/2020) y hasta el pasado 11 de mayo no se ha iniciado la desescalada del confinamiento, la fase 1 , en algunas regiones sanitarias. Casi dos meses, durante los cuales 47 millones de ciudadanos se han visto obligados a permanecer el máximo de tiempo posible en sus casas.

Este encierro es una situación excepcional que ha causado nuevos modelos de vida, nuevos hábitos de consumo, y en particular, nuevos consumos de los medios de comunicación, así como del entretenimiento, del ocio y de la cultura.

La ciudadanía confinada disponía de mucho tiempo para informarse y entretenerse, de modo que investigar los cambios producidos por la pandemia y los hábitos adquiridos durante las semanas de estado de alarma son de interés para detectar tendencias, nuevos intereses, distribución de tiempos de visionado o escucha, a la vez que hacer una comparativa entre "targets". 
La investigación quiere analizar el impacto de la pandemia del Coronavirus en los hábitos y el consumo de medios en España, a partir de una encuesta a la población. Para llevarlo a cabo el artículo se divide en 4 partes, además de la introducción y bibliografía; en la primera se presenta el estado de la cuestión, sitúa el contexto actual la sociedad red y recoge las investigaciones sobre los hábitos y consumos de medios. El segundo bloque detalla la metodología utilizada; a continuación sigue la presentación y análisis de los resultados de la encuesta, y cierra el artículo con la discusión y principales aportaciones.

\subsection{Estado de la cuestión}

Vivimos sumergidos en un panorama mediático competitivo, saturado de contenidos -existe una hibridación entre los medios tradicionales y los digitales que produce una complementariedad de los mismos, en el proceso de recopilación de información- y dónde es difícil decidir qué información escoger. A esta desinformación creciente e incremento de noticias falsas se le añade una falta de confianza a los medios tradicionales. En la actualidad, la ciudadanía se dirige a los medios y no a los contenidos, y en esta oferta (cantidad y calidad) y demanda (hábitos de consumo, prácticas informativas) de información vemos condicionadas las opiniones y el comportamiento cívico y político de la población (Casero-Ripollès, 2020).

La participación de la ciudadanía en la sociedad actual va en aumento, tal y como expresa Livingstone (2013), el entorno mediático actual está remodelando las estructuras de oportunidades mediante las cuales las personas (como audiencias y públicos mediados) pueden participar en una sociedad cada vez más mediatizada. Por otro lado, el poder y elevada presencia de los líderes de opinión también determina la dieta mediática: "There is a widespread presence of opinion leaders in the respondents' social media feeds, bringing attention to news they otherwise would have missed, and just as important, delivering interpretation and context” (Bergström \& Belfrage, 2018:1).

Al escenario mencionado le tenemos que sumar una crisis global, iniciada como una crisis sanitaria con la pandemia de la Covid-19 que llegó a España a mitad del mes de marzo. Según la Organización Mundial de la Salud: en salud, los conceptos crisis y comunicación están relacionados, y convierten a la comunicación en una importante aliada para la gestión política, social, institucional y sanitaria.

\subsection{Hábitos y consumo de información}

Tener conciencia del modelo de sociedad comunicativa en qué nos encontramos nos ayuda entender más y mejor el consumo de medios de comunicación. Los consumidores españoles eligen cada vez más Internet frente a la televisión; la popularidad de los dispositivos móviles y las redes sociales fomenta un consumo de medios cada vez más fragmentado y multipantalla; mientras se impone el contenido visual y generado por los usuarios, el cual incorporan incluso los medios más tradicionales (AIMC, 2020).

Las nuevas tendencias y pautas de consumo están marcadas por una gran variedad de factores que generan nuevos estilos de vida. Entre ellos están una mayor formación y un mayor poder adquisitivo, cambios en la composición de los hogares (edad más tardía en ser padres, incorporación de la mujer al mundo laboral, posesión de dispositivos digitales, mayor formación digital); hábitos de consumo (cada vez se difumina más el tiempo dedicado al ocio y al trabajo); el gasto de equipamiento de las viviendas ha incrementado. Los cambios sociodemográficos, en los últimos años la composición de los hogares se ha modificado, cada vez hay más hogares y menos miembros por hogar, y la tipología de familia también ha cambiado aumentando el número de familias monoparentales. La incorporación de la mujer al mercado de trabajo también es una tendencia fundada en nuestro 
tiempo, y eso repercute en las formas de consumo en la unidad familiar. Los lugares de compra, aunque hoy en día el mayor volumen de compras todavía se realiza offline, muchos son los internautas que buscan información pre-compra en Internet.

El nuevo consumidor tiene nuevas formas de comportamiento asociadas a un perfil de usuario más informado, con mayor nivel de formación, más reflexivo, que busca minimizar los riesgos, y que quiere seguridad y simplicidad en el proceso de compra. Con las TIC el consumidor tiene a su alcance multitud de inputs para poder comparar un mismo producto y poder saber de él a través de la red social y la interacción con otras personas. El nuevo prosumidor fundamenta su decisión de compra a partir de la información recopilada de las redes sociales. Las nuevas formas de consumo: el consumo colaborativo, consumo sostenible, consumo responsable y comercio justo son ejemplos del auge que está teniendo las nuevas formas de consumir de manera más responsable, cooperativa y beneficiosa para todos; y las plataformas digitales ayudan a beneficiar esa tipología de consumo. La globalización, nos proyectamos hacia un consumidor global debido principalmente a la composición multicultural de la población y al acceso a la Red.

Los datos del Observatorio Nacional de Telecomunicaciones y de la Sociedad de la Información (2019), correspondientes al 2018, indican que 18,1 millones de hogares $(98,0 \%)$ cuentan con telefonía móvil y 15,9 millones $(86,0 \%)$ con servicios de telefonía fija. Los hogares que disponen de Internet son 15,2 millones $(82,2 \%)$ y la TV de pago está contratada en 7,5 millones de hogares (40,5\%), siendo la fibra la tecnología mayoritaria. La frecuencia de uso de internet es bastante intensiva, ya que un 83,3\% de los internautas declaran acceder a Internet a diario o casi a diario y un $72,7 \%$ el día anterior. El uso de internet se sitúa en 34,2 millones de internautas, es decir, el $87 \%$ de la población y el 83,7\% lo utiliza para buscar información. Estas conexiones se siguen realizando desde los mismos lugares; la propia casa $(93,5 \%)$, casa de amigos o familiares $(39,9 \%)$ y desde el trabajo $(40,1 \%)$. Se acentúa aún más la preferencia del teléfono móvil como dispositivo de acceso a la Red. La suscripción a contenidos de video "streaming" en esta oleada se sitúa en el 10,9\% de los hogares españoles, aumentando la convivencia de este servicio con los de televisión de pago; un $8,6 \%$ declara tener ambos servicios contratados.

Algunos de los hábitos de visionado, junto con la naturaleza de los contenidos televisivos y también el consumo en multipantalla son algunos de los cambios más importantes. El $60 \%$ de quienes ven la televisión lo hacen mientras usan una red social. De este grupo, el $40 \%$ comenta lo que está viendo en televisión en las redes sociales. Más de la mitad de individuos de entre 16 y 24 años usa de forma habitual dispositivos complementarios para hablar con otros de lo que están viendo en televisión a través de mensajes de texto, correo electrónico, Facebook o Twitter (Hirshberg, 2004). El promedio de tiempo diario destinado al consumo de medios de comunicación en España está encabezado con 212,9 minutos en televisión y en segunda posición 161,2 minutos en internet (Statista, 2020).

La mayoría de medios tradicionales están perdiendo poco a poco relevancia en favor, esencialmente, del uso de Internet, que se consolida como el medio más valorado por los consumidores. Una de las consecuencias de este cambio de tendencia, que ya es un hecho, es el posicionamiento del "smartphone" como dispositivo de mejor valorado, en lugar de la televisión. Las previsiones para el 2020, antes del inicio de la pandemia, apuntaban al crecimiento de internet y las compras online; la tendencia imparable del aumento del "smartphone", las suscripciones y servicios "online" y las plataformas colaborativas "online" (Epdata, 2020). 


\subsection{Consumo de medios en momentos de crisis}

El grado de dependencia de la sociedad con los medios de comunicación viene determinado principalmente por la situación de cambio que se está experimentando, la presencia de conflictos o inestabilidad y la importancia de los medios como fuente principal de información (Ball-Rokeach \& DeFleur, 1979; McQuail \& Windahl, 1993). El entorno socioestructural es un factor determinante a tener en cuenta. Un país como China, durante la crisis de salud pública de 2003, sin un libre flujo de información, propició que los ciudadanos participasen en la búsqueda de información en recursos alternativos como los servicios de mensajes cortos (SMS) e internet, e incluso crearan canales de información alternativos siendo productores $\mathrm{y}$ divulgadores. Internet fue una herramienta especialmente poderosa para permitir que estos ciudadanos pudiesen eludir el control oficial y desafiar la información oficial durante la crisis (Tai \& Sun, 2007).

En la sociedad occidental, los medios tienen la necesidad de explicar a la ciudadanía lo que ocurre. La excepcionalidad del momento potencia la información periodística que, con los comunicados oficiales y otras retransmisiones en directo, rompen con la regularidad de la programación. La rareza aumenta el valor de lo escaso. Estas retransmisiones se presentan como productos audiovisuales poco habituales pero de gran interés (Dayan \& Katz, 1995; Blanco, 1999).

Durante esta epidemia, la sobreproducción de artículos académicos ha posicionado a los científicos como líderes de opinión (Costa-Sánchez, 2020). Como afirma Cowper (2020:1). "Scientists, technocrats, and other experts could become the stars of 2020. The public's reaction to the communications efforts so far will be crucial to deciding how events proceed in the 'contain' stage of the national strategy, which is to be followed by 'delay spread,' and then 'do the science and research' and 'mitigate impact on the NHS'. Además, se considera que la cobertura de los medios es una manera efectiva de mitigar la propagación de la enfermedad durante la fase de propagación del brote (Zhou, 2020). "The overwhelming amount of information and the overuse of mass media in communicating the Covid-19 virus might contribute to overreaction, unwarranted public fear, and an overly pessimistic feeling in perceiving the current risk" (Huynh, 2020:5).

En este contexto, los hábitos y tendencias de consumo se han visto drásticamente modificados debido a la pandemia y las medidas de confinamiento decretadas por el gobierno, de manera que el consumo de televisión y medios digitales se ha disparado durante el confinamiento. Los diarios digitales reciben un $45 \%$ más de páginas vistas y han incrementado su tráfico un 100\%, la audiencia digital de la radio online crece en un $112 \%$ (y se posiciona como uno de los medios que da más confianza a la audiencia (Rodero, 2020) y la televisión "online" en directo suma un 93\% de usuarios únicos. Por su parte, la televisión se ha convertido también en la fuente principal de entretenimiento e información (Crónica Digital, 2020).

Los incrementos más relevantes se registran entre los jóvenes de entre 13 y 24 años y, por franjas horarias. Las mañanas, sobremesa y tardes son las franjas que más aumentan, alrededor de un $25 \%$ del total de la población. Por otro lado, también están experimentando un gran crecimiento los informativos, con un aumento del $65 \%$ en su consumo diario. Y, sorprendentemente, también aumenta el consumo de los religiosos, que han crecido un $80 \%$. Otros hábitos recuperados son la creación de comunidades digitales, el aumento de la audiencia de los "e-games", el alza de la tendencia "Do It Yourself", el "balconing" como nueva forma de socializar y el humor como vía de escape. Sobre las consecuencias económicas a nivel internacional, se prevé que la tasa de crecimiento del PIB mundial será la más baja en 30 años, alrededor del 2\%; mientras que se recuerda que en España el Ibex ha caído un $9,1 \%$ en cuatro sesiones y, en las seis últimas jornadas, el descenso es del 11,15\%, su mayor retroceso desde 2011. 
Dentro de la "nueva normalidad" en el consumo de medios, las audiencias siguen más elevadas que en pre-aislamiento, aunque con las fases de desconfinamiento y la apertura al trabajo a más sectores, se observa ya una ligera bajada. La televisión baja de los 9 millones de audiencia media diaria y de los 300 minutos de consumo. Siguen elevados los otros usos de la televisión, como los videojuegos y plataformas de pago. En internet, el tiempo diario de conexión sigue elevado, aunque el número de páginas vistas se reduce ligeramente, sobre todo fines de semana.

Todo los estudios coinciden en que habrá un antes y un después en la actitud mental de los consumidores, ya sea provocada por la reflexión de este largo encierro (que lleva a replantearse comportamientos de consumo y de estilo de vida, dejando en evidencia lo prescindible de algunos) o bien por el propio contexto económico, que inquieta a muchos y les hace replantear sus gastos. Los hábitos dentro del hogar y en las fases de desconfinamiento volverán a mostrar cambios y tendencias de consumo.

\section{Metodología}

Se suministró un cuestionario auto-administrado online secuencial representativo de la población española ( $\mathrm{N}=1,500$ participantes) durante los primeros días de cuarentena (13 al 30 de marzo 2020). La muestra se subdividió según las variables edad, 18-39 años $(\mathrm{N}=720)$ y más de 40 años $(\mathrm{N}=780)$ y género, mujeres $(\mathrm{N}=750)$ y hombres $(\mathrm{N}=750)$, para detectar las especificidades más relevantes de cada colectivo. El error muestral se sitúa en el $\pm 4,38 \%$ al $95 \%$ de confianza.

Para los datos de audiencia televisiva se ha consultado la base de datos de Kantar Media para el mismo periodo estudiado.

\section{Resultados}

Todos los públicos estudiados conocieron la existencia del coronavirus a través de la televisión principalmente (Tabla 1). En el caso de los hombres de 18-70 años, destaca también la prensa online (47.8\%), internet $(44.7 \%)$ y los comunicados de fuentes oficiales $(42.1 \%)$. Las mujeres de $18-70$ años conocieron la presencia de un nuevo virus a través de TV $(87.2 \%)$, comunicados de fuentes oficiales $(40.6 \%)$ y redes sociales $(37.3 \%)$. Según la variable de edad, los más jóvenes, individuos de 18 a 39 años, se enteraron a través de la TV (84.4\%), redes sociales $(40.0 \%)$, prensa online $(37.9 \%)$ y comunicados oficiales (36.8\%). Los individuos de más edad, de 40 a 70 años, se informaron sobre el virus, en un primer momento, a través de la televisión (88.2\%), comunicados oficiales (45.6\%), prensa en línea $(43.6 \%)$ y radio $(39.5 \%)$. 
RLCS, Revista Latina de Comunicación Social, 78, 155-167

[Investigación] DOI: 10.4185/RLCS-2020-1472| ISSN 1138-5820| Año 2020

Tabla 1. Comparativa del porcentaje de uso de los medios de comunicación segmentada por los públicos estudiados

\begin{tabular}{|c|c|c|c|c|c|}
\hline & $\begin{array}{l}\text { Total Ind. } \\
N=1.500\end{array}$ & $\begin{array}{c}\text { Hombres 18-70 } \\
N=750\end{array}$ & $\begin{array}{c}\text { Mujeres 18-70 } \\
N=750\end{array}$ & $\begin{array}{c}\text { Ind. 18-39 } \\
N=720\end{array}$ & $\begin{array}{c}\text { Ind. 40-70 } \\
N=780\end{array}$ \\
\hline \multicolumn{6}{|l|}{ ¿Cómo conociste el Coronavirus? A través de... } \\
\hline Televisión & 86,4 & 85,6 & 87,2 & 84,4 & $\mathbf{8 8 , 2}$ \\
\hline Prensa online & 40,9 & 47,8 & 33,9 & 37,9 & 43,6 \\
\hline Radio & 31,2 & $\mathbf{3 8 , 1}$ & 24,2 & 23,2 & 38,5 \\
\hline Internet (buscadores, webs, blogs, foros...) & 38,8 & $\mathbf{4 4 , 7}$ & 33,0 & 39,8 & 38,0 \\
\hline Comunicados de fuentes oficiales (Ministerio de Sanidad, OMS.. & 41,4 & 42,1 & 40,6 & 36,8 & 45,6 \\
\hline Redes sociales (Twitter, Facebook, Instagram...) & 37,0 & 36,6 & 37,3 & 40,0 & 34,3 \\
\hline Familiares/Amigos/Conocidos & 31,7 & 33,2 & 30,1 & 32,7 & 30,7 \\
\hline Prensa en papel & 20,7 & 25,6 & 15,7 & 16,4 & 24,6 \\
\hline Otros medios & 1,3 & 1,0 & $\mathbf{1 , 5}$ & 0,7 & 1,8 \\
\hline \multicolumn{6}{|c|}{ ¿Qué medios utilizas para mantenerte informado/a del avance del virus? } \\
\hline Televisión & 83,2 & 82,6 & 83,8 & 78,6 & 87,5 \\
\hline Prensa online & 49,8 & 55,7 & 44,0 & $\mathbf{5 0 , 0}$ & 49,6 \\
\hline Comunicados de fuentes oficiales (Ministerio de Sanidad, OMS.. & 50,3 & 47,4 & 53,3 & 46,9 & $\mathbf{5 3 , 5}$ \\
\hline Internet (buscadores, webs, blogs ...) & 41,8 & 43,8 & 39,8 & 43,1 & 40,6 \\
\hline Redes sociales (Twitter, Facebook, Instagram...) & 35,5 & 33,0 & 37,9 & 40,5 & 30,8 \\
\hline Radio & 29,0 & 35,5 & 22,4 & 18,2 & 38,9 \\
\hline Familiares/Amigos/Conocidos & 22,0 & 21,6 & 22,3 & 22,2 & 21,7 \\
\hline Prensa en papel & 9,5 & 12,2 & 6,8 & 8,1 & $\mathbf{1 0 , 8}$ \\
\hline Otros & 1,1 & 0,3 & 1,9 & 0,9 & 1,3 \\
\hline No me informo & 0,7 & 0,9 & 0,5 & $\mathbf{0 , 8}$ & 0,7 \\
\hline
\end{tabular}

Fuente: Datos facilitados por Havas Media, elaboración propia.

A medida que avanzó el alcance de la pandemia, el consumo de medios realizado para mantenerse informado ha ido consolidando 3 fuentes: la televisión, los comunicados oficiales y la prensa en línea (Tabla 1). Éstas coinciden en ser las más utilizadas por los colectivos estudiados, aunque su consumo varía ligeramente de unos a otros. Por género, vemos que los hombres de 18 a 70 años, se han informado a través de la televisión (82.6\%), prensa en línea $(55.7 \%)$ y comunicados oficiales (47.4\%) principalmente. Las mujeres de 18 a 70 años han utilizado sobretodo televisión (83.8\%), comunicados de fuentes oficiales $(53.3 \%)$ y prensa online $(44.0 \%)$. Por edades, destaca la televisión (78.6\%), prensa en línea $(50.0 \%)$ y comunicados de fuentes oficiales (46.9\%) entre los más jóvenes y TV $(87.5 \%)$, comunicados de fuentes oficiales $(53.5 \%)$ y prensa online $(49.6 \%)$ entre los mayores.

Los medios menos utilizados para informarse de la evolución del Coronavirus, por todos los colectivos estudiados, serían internet, redes sociales, radio, familiares/conocidos y prensa en papel.

Aunque no destaca el consumo de la radio para mantenerse informado sobre la evolución del virus, este medio destaca por ser el considerado como más creíble, conjuntamente con la televisión para el de la total población (Tabla 2). Estos dos medios serían los que generarían más confianza entre los colectivos estudiados seguidos, de cerca, por la prensa, tanto en formato digital como en papel.

Tabla 2. Comparativa del nivel de confianza en los medios de comunicación según los públicos estudiados

\begin{tabular}{|c|c|c|c|c|c|}
\hline & $\begin{array}{c}\text { Total Ind. } \\
N=500\end{array}$ & $\begin{array}{c}\text { Hombres 18-70 } \\
N=250 \\
\end{array}$ & $\begin{array}{c}\text { Mujeres 18-70 } \\
\quad N=250\end{array}$ & $\begin{array}{c}\text { Ind. 18-39 } \\
N=240\end{array}$ & $\begin{array}{c}\text { Ind. } 40-70 \\
N=260\end{array}$ \\
\hline \multicolumn{6}{|c|}{ ¿Qué medios te parecen más creíbles para informarte sobre el coronavirus? Puntúa del 1 al 7 (1=mínimo, 7=máximo) } \\
\hline Radio & 5,3 & 5,4 & 5,2 & 5,0 & 5,5 \\
\hline Televisión & 5,3 & 5,1 & 5,4 & 5,1 & $\mathbf{5 , 4}$ \\
\hline Prensa en papel & 5,1 & 5,0 & 5,2 & 5,0 & 5,2 \\
\hline Prensa online & 5,1 & 5,0 & 5,2 & 5,1 & 5,1 \\
\hline Internet & 4,2 & 4,0 & 4,4 & 4,5 & 3,9 \\
\hline Familiares/Amigos/Conocidos & 4,0 & 3,9 & 4,1 & 4,1 & 4,0 \\
\hline Redes sociales & 3,5 & 3,1 & 3,8 & $\mathbf{3 , 8}$ & 3,2 \\
\hline
\end{tabular}

Fuente: Datos facilitados por Havas Media, elaboración propia. 
RLCS, Revista Latina de Comunicación Social, 78, 155-167

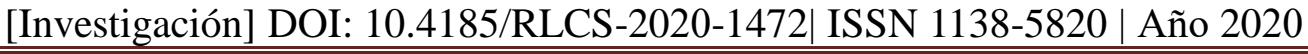

Se ha realizado un foco en el estudio del consumo televisivo durante este periodo por ser el medio más utilizado. Los datos de Kantar Media afirman que el consumo televisivo ha incrementado de forma considerable para todos los targets, resultado que es lógico y de sentido común debido al confinamiento, pero queremos destacar el $147 \%$ de crecimiento para el colectivo de 18 a 39 años y el $82 \%$ para los hombres de 18 a 70 años (Tabla 3), de modo que las personas que ya se informaban, ahora lo hacen con más frecuencia, ya sea por tiempo y también para tener conocimiento sobre la evolución de la pandemia, y poder actuar con el máximo conocimiento a su alcance.

Tabla 3. Audiencia media televisiva (en miles) por los distintos públicos estudiados

\begin{tabular}{|c|c|c|c|c|c|}
\hline & Total Ind. & Hombres adultos & Mujeres adultas & Ind. 18-39 & Ind +40 años \\
\hline Periodo $13 / 03 / 2020$ a $19 / 04 / 2020$ & 8.613 & 3.969 & 4.644 & 1.611 & 7.002 \\
\hline Crecimiento respecto periodo anterior (21/02/2020-12/03/2020) & $63 \%$ & $82 \%$ & $\mathbf{5 0 \%}$ & $147 \%$ & $53 \%$ \\
\hline
\end{tabular}

Fuente: Kantar Media

La audiencia por cadenas se muestra variable según el género, siendo Antena 3 la más vista entre los hombres adultos (Tabla 4). Le siguen La 1 y las autonómicas. En el caso de las mujeres, lidera la audiencia Telecinco, seguido de Antena 3 y La 1. Por edades, no hay diferencias significativas.

Tabla 4. Audiencia media televisiva (en miles) por cadenas según los distintos públicos estudiados

\begin{tabular}{|c|c|c|c|c|c|}
\hline Cadenas & Total Ind. & Hombres adultos & Mujeres adultas & Ind. 18-39 & Ind +40 años \\
\hline Total TV & 8.729 & 3.999 & 4.730 & 1.649 & 7.079 \\
\hline $\mathrm{T} 5$ & 1.220 & 397 & 823 & 213 & 1.007 \\
\hline $\mathrm{A} 3$ & 1.028 & 443 & 585 & 178 & 850 \\
\hline La1 & 925 & 410 & 515 & 137 & 787 \\
\hline Autonómicas & 810 & 380 & 430 & 132 & 679 \\
\hline \begin{tabular}{|l|} 
La Sexta \\
\end{tabular} & 795 & 406 & 389 & 158 & 637 \\
\hline Temáticas de pago & 732 & 385 & 347 & 165 & 566 \\
\hline Cuatro & 461 & 220 & 241 & 93 & 368 \\
\hline $\mathrm{La} 2$ & 248 & 131 & 117 & 27 & 221 \\
\hline
\end{tabular}

Fuente: Kantar Media

El tipo de programas televisivo de más audiencia durante el confinamiento ha sido los infoshows seguidos de los informativos para todos los colectivos estudiados (Tabla 5).

Tabla 5. Audiencia media televisiva (en miles) por tipología de programa según los distintos públicos estudiados

\begin{tabular}{|c|c|c|c|c|c|}
\hline Tipo de programa & Total Ind. & Hombres adultos & Mujeres adultas & Ind. 18-39 & Ind +40 años \\
\hline Infoshow & 350 & 120 & 230 & 63 & 287 \\
\hline Información & 222 & 104 & 117 & 39 & 182 \\
\hline Concursos & 170 & 73 & 98 & 26 & 144 \\
\hline Religiosos & 155 & 58 & 97 & 10 & 145 \\
\hline Misclenánea & 88 & 40 & 48 & 16 & 72 \\
\hline Ficción & 60 & 28 & 32 & 12 & 49 \\
\hline Culturales & 37 & 20 & 17 & 5 & 32 \\
\hline Toros & 15 & 9 & 6 & 1 & 14 \\
\hline Deportes & 10 & 7 & 3 & 2 & 9 \\
\hline Musicales & 5 & 3 & 3 & 1 & 4 \\
\hline
\end{tabular}

Fuente: Kantar Media

En referencia a los programas informativos, los que han conseguido más audiencia han sido los de Telecinco para todos los colectivos estudiados a excepción de los hombres adultos, que han optado 
por Antena 3 (Tabla 6). Los informativos de La 1 de Televisión Española se sitúan en cuarta posición, muy por debajo en audiencia de las cadenas líderes privadas.

Tabla 6. Audiencia media televisiva (en miles) de programas informativos por cadenas según los distintos públicos estudiados

\begin{tabular}{|c|c|c|c|c|c|}
\hline Cadena & Total Ind. & Hombres adultos & Mujeres adultas & Ind. 18-39 & Ind +40 años \\
\hline \begin{tabular}{|l|} 
T5 \\
\end{tabular} & 1.401 & 500 & 901 & 265 & 1.136 \\
\hline \begin{tabular}{|l|} 
La Sexta \\
\end{tabular} & 1.274 & 652 & 622 & 252 & 1.023 \\
\hline A3 & 1.098 & 502 & 597 & 208 & 890 \\
\hline La1 & 696 & 320 & 376 & 105 & 592 \\
\hline Cuatro & 351 & 173 & 177 & 83 & 268 \\
\hline \begin{tabular}{|l|}
$\mathrm{La} 2$ \\
\end{tabular} & 141 & 79 & 62 & 17 & 124 \\
\hline Autonómicas & 62 & 29 & 33 & 11 & 51 \\
\hline Temáticas de Pago & 4 & 2 & 2 & 1 & 3 \\
\hline
\end{tabular}

Fuente: Kantar Media

También se ha analizado el consumo de plataformas over-the-top (OTT), en este caso Netflix, Movistar, Vodafone, HBO y Amazon. Las plataformas y aplicaciones over-the-top, o plataformas OTT, son aplicaciones que ofrecen contenido de video a través de internet en lugar de televisión por cable o satélite (la forma tradicional). Permiten transmitir instantáneamente videos en dispositivos móviles (Smartphones y tablets), web y televisores que utilizan dispositivos como Chromecast, AppleTV y Amazon Fire TV, así como SmartTVs. Los datos evidencian un alto incremento en todos los colectivos estudiados, sobre todo entre los individuos de 18 a 39 años (+53\%) (Tabla 7).

Tabla 7. Audiencia media televisiva (000) de las plataformas OTT según los distintos públicos estudiados

\begin{tabular}{|c|c|c|c|c|c|}
\hline & Total Ind. & Hombres adultos & Mujeres adultas & Ind. 18-39 & Ind +40 años \\
\hline Total TV & 8.613 & 3.969 & 4.512 & 1.611 & 7.002 \\
\hline \begin{tabular}{|l|} 
Consumo OTT \\
\end{tabular} & 3.213 & 1.498 & 1.769 & 859 & 2.354 \\
\hline$\%$ peso OTT & $37 \%$ & $38 \%$ & $39 \%$ & $53 \%$ & $34 \%$ \\
\hline
\end{tabular}

Fuente: Kantar Media

\section{Discusión y conclusiones}

Esta investigación pone en relevancia la importancia de la televisión por delante del resto de medios. Este dato parece contradecirse con estudios anteriores que afirmaban que la televisión había perdido la audiencia joven a favor de los medios digitales (Mumtaz; Karamat; Iqbal, 2019; Sedláček, 2016). El estudio apunta que en momentos críticos, la ciudadanía, de todas las edades, prefiere informarse a través del tradicionalmente conocido modo medio rey, y descartando sobre todo internet, redes sociales y aquella información recibida por parte de conocidos. La radio, tal y como afirma Rodero (2020), y la televisión son los medios de mayor confianza depositada por la población, y, las redes sociales el de menor, a pesar del uso ascendiente y continuado en los últimos años (AIMC, 2020).

El auge de las fake news y bulos por internet podría ser una de los principales motivos de desconfianza. Estudios anteriores han demostrado que la exposición a noticias falsas conduce a niveles más bajos de confianza en los medios y a una identificación menos precisa de noticias reales (Van Duyn \& Collier, 2019). También se ha percibido una correlación entre las redes sociales y la difusión de noticias falsas (Nielsen \& Graves, 2017; Rodríguez-Fernández, 2019). Como la misma UNESCO (2020) reconocía, las noticias falsas se han propagado de forma más rápida y peligrosa que el propio virus durante este periodo, y han debilitado la información relativa a la toma de precauciones sanitarias procedente de los servicios sanitarios (O’Connor, \& Murphy, 2020). 
En esta línea, es relevante destacar el papel de los comunicados oficiales en directo, como pieza televisiva poco habitual pero de gran interés (Dayan \& Katz, 1995; Blanco, 1999). La prensa online y la radio también se han consolidado como grandes medios informativos, aunque existen matices entre la audiencia de los targets analizados. Igual que concluye Masip et al (2020) detectamos la "tendencia a refugiarse en medios reconocidos, fundamentalmente informativos de televisiones públicas y las versiones digitales de periódicos tradicionales".

Lázaro-Rodríguez (2020) señala ya el rol esencial de los medios digitales, que son los más usados para publicar sobre el Covid-19, a la hora de cubrir las necesidades de información de la población. Estos medios, siendo los que más contenido informativo sobre el virus registran, no han conseguido liderar en generación de confianza y credibilidad. Uno de los motivos podría ser que el público, en general, se ha visto abrumado por la cantidad de información relacionada con el nuevo virus (Tanne et. Al, 2020). Los datos de la encuesta no entran a analizar los contenidos de la parrilla televisiva de las cadenas, pero para un posterior estudio sería de interés tener una visión más amplia para obtener justificar los comportamientos en función del género, así como la valoración de la audiencia por la cobertura realizada, es decir si cumplen la función de servicio de información o contribuyen a aumentar la alarma social.

Dentro del liderazgo del medio televisivo, es relevante destacar que los programas tipo infoshows son los que más audiencia consiguen, por encima de los informativos tradicionales. En este sentido, tal y como ha pasado en otros momentos de catástrofe o crisis la información es relevante y prioritaria, pero la población también necesita compaginarla con el humor y entretenimiento, para poder evadirse de la crudeza de las noticias relacionadas con la COVID-19. Aunque no es el foco de la investigación, la necesidad de tener información permanente ha causado una sobreinformación, junto los contenidos falsos que se distribuyen por redes sociales y otras plataformas, también han jugado un rol relevante durante el confinamiento. Estos datos podrían dejar ver una nueva tendencia en la programación informativa para recuperar así los targets más jóvenes que había perdido en años anteriores. Los niños/as y jóvenes escolarizados han encontrado en la televisión un espacio de formación con la programación incorporada en la parrilla televisiva. La recuperación de los targets más jóvenes, juntamente con el auge de las plataformas OTT, muestra cómo la era post Covid-19 consolida un panorama mediático todavía más competitivo y saturado de contenidos. El aumento de suscriptores de las plataformas OTT conseguido durante la cuarentena abre un interrogante sobre la continuidad de los mismos una vez se vuelva a la denominada "nueva realidad".

\section{Bibliografía}

Asociación para la investigación de medios de comunicación (AIMC) (2020). AIMC Cuaderno de Bitácora: Semana 4 de Confinamiento (S4C) https://www.aimc.es/a1mcc0nt3nt/uploads/2020/04/2020_04_16_NP_AIMC_Cuaderno_de_Bitacora_sem1_s4c.pdf

Ball-Rokeach, S.J. \& M.L. DeFleur (1979) ‘A Dependency Model of Mass-media Effects', en Gary Gumpert (ed.) Inter/Media, pp. 81-96. New York: Free Press.

Blanco, J.M. (1999): El directo: análisis de una situación informativa privilegiada (o "carpe diem". Revista Latina de Comunicación Social, 19. Recuperado de http://www.revistalatinacs.org/a1999fjl/72bla.htm 
Bergström, A. \& Jervelycke Belfrage, M. (2018). "News in Social Media". Digital Journalism, 6(5), 583-598. https://doi.org/10.1080/21670811.2018.1423625

Casero-Ripollés, A. (2020). "Impact of Covid-19 on the media system. Communicative and democratic consequences of news consumption during the outbreak". El profesional de la información, 29(2), e290223. https://doi.org/10.3145/epi.2020.mar.23

Costa-Sánchez, C. y López-García, X. (2020). "Comunicación y crisis del coronavirus en España. Primeras lecciones". El profesional de la información, 29(3), e290304. https://doi.org/10.3145/epi.2020.may.04

Cowper, A. (2020). "Covid-19: are we getting the communications right?" BMJ 2020;368:m919. https://doi.org/10.1136/bmj.m919

Crónica Digital (2020). https://cronicaglobal.elespanol.com/vida/aumenta-consumo-televisionmedios-digitales-durante-confinamiento 331059 102.html

Dayan, D., \& Katz, E., (1995) La historia en directo. La retransmisión televisiva de los acontecimientos. Gustavo Gili, Barcelona.

Epdata (2020). Tendencias de consumo de radio en España, datos y gráficos. https://www.epdata.es/datos/tendencias-consumo-radio-espana-datos-graficos/300

Hirshberg, P. (2014). "Primero los medios y luego nosotros. Cómo ha cambiado internet la naturaleza fundamental de la comunicación y su relación con el público". En: Benckler, et al. (2014). C@mbio 19 ensayos fundamentales sobre cómo internet está cambiando nuestras vidas BBVA.

Huynh, T.L.D (2020). "The COVID-19 risk perception: A survey on socioeconomics and media attention". Econ. Bull, 40(1), 758-764. Recuperado de https://EconPapers.repec.org/RePEc:ebl:ecbull:eb-20-00175

Lázaro-Rodríguez, P. y Herrera-Viedma, E. (2020). "Noticias sobre Covid-19 y 2019-nCoV en medios de comunicación de España: el papel de los medios digitales en tiempos de confinamiento". El profesional de la información, 29(3), e290302. https://doi.org/10.3145/epi.2020.may.02

Livingstone, S. (2013). "The participation paradigm in audience research". The communication review, 16(1-2), 21-30. https://doi.org/10.1080/10714421.2013.757174

Masip, P. Aran-Ramspott, S. Ruiz-Caballero, C., Suau, J., Almenar, E. y Puertas-Graell, D. (2020). "Consumo informativo y cobertura mediática durante el confinamiento por el Covid-19: sobreinformación, sesgo ideológico y sensacionalismo". El profesional de la información, 29(3), e290312. https://doi.org/10.3145/epi.2020.may.12

McQuail, D. \& S.Windahl (1993). Communication Models for the Study of Mass Communication. Nueva York: Longman. 
Mumtaz, T.; Karamat, K. \& Iqbal, A. (2019). "A comparative study of traditional and social media consumption patterns among youth". Journal of Media Studies, 30(2). Recuperado de http://journals.pu.edu.pk/journals/index.php/jms/article/view/2011

Nielsen, R.K. \& Graves, L. (2017). "News you don't believe": Audience perspectives on fake news. Oxford: Reuters Institute for the Study of Journalism.

O'Connor, C., \& Murphy, M. (2020). Going viral: doctors must tackle fake news in the covid-19 pandemic. BMJ, 24(369), m1587. https://doi.org/10.1136/bmj.m1587

Observatorio Nacional de Telecomunicaciones y de la Sociedad de la Información (ONTSI) (Ed.) (2019). Las TIC en los hogares españoles. Estudio de demanda y uso de Servicios de Telecomunicaciones y Sociedad de la Información. https://www.ontsi.red.es/sites/ontsi/files/201906/LXIOleadaPanelHogares.pdf

Rodero, E. (2020). "La radio: el medio que mejor se comporta en las crisis. Hábitos de escucha, consumo y percepción de los oyentes de radio durante el confinamiento por el Covid-19". El profesional de la información, 29(3), e290306. https://doi.org/10.3145/epi.2020.may.06

Rodríguez-Fernández, L. (2019): "Desinformación y comunicación organizacional: estudio sobre el impacto de las fake news". Revista Latina de Comunicación Social, 74, 1714-1728. https://doi.org/10.4185/RLCS-2019-1406

Sedláček, J. (2016). The Rise of the YouTube Celebrity: The Migration of Young Audiences from TV to Independent Content Creators. Univerzita Karlova.

Statista (2020). Consumo diario de medios de comunicación en España. https://es.statista.com/estadisticas/491058/consumo-diario-de-medios-de-comunicacion-enespana-por-tipo

Tanne, J. H., Hayasaki, E., Zastrow, M., Pulla, P., Smith, P., Rada, A. G., et al. (2020). Covid-19: how doctors and healthcare systems are tackling coronavirus worldwide. BMJ 2020;368:m1090. https://doi.org/10.1136/bmj.m1090

Tai, Z., \& Sun, T. (2007). Media dependencies in a changing media environment: the case of the 2003 SARS epidemic in China. New Media \& Society, 9(6), 987-1009. https://doi.org/10.1177/1461444807082691

UNESCO (2020). Audio resources to counter disinformation. https://en.unesco.org/covid19/communicationinformationresponse/audioresources

Van Duyn, E., \& Collier, J. (2019). Priming and fake news: The effects of elite discourse on evaluations of news media. Mass Communication and Society, 22(1), 29-48. https://doi.org/10.1080/15205436.2018.1511807

Zhou, W., Wang, A., Xia, F. \& Yanni T. (2020). "Effects of media reporting on mitigating spread of COVID-19 in the early phase of the outbreak". Mathematical Biosciences and Engineering, 17(3), 2693-2707. https://doi.org/10.3934/mbe.2020147 


\section{AUTOR/ES:}

\section{Mireia Montaña Blasco}

Doctora en Comunicación. Su actividad de I+D+i se centra en el impacto de tienen los medios de comunicación en el bienestar de las personas, sobre todo en aquellos colectivos más vulnerables: niños, jóvenes y mayores. Después de años vinculada a la práctica profesional en agencias de publicidad, en 2003 se incopora a la Universitat de Vic como profesora agregada. En 2008 se incorpora como profesora la Universidad Oberta de Catalunya. De 2010 a 2016, ejerce de directora del Posgrado en Publicidad en internet y otros medios digitales. Forma parte del Grupo de investigación en Aprendizajes, medios de comunicación y entretenimiento (GAME) de la Universitat Oberta de Catalunya y del Grupo Communication, Advertising \& Society (CAS) de la Universitat Pompeu Fabra.

mmontanabl@uoc.edu

\section{Índice H: 3}

Orcid ID: https://orcid.org/0000-0002-6464-5129

Google Scholar: https://scholar.google.es/citations?user=VSX3qhQAAAAJ\&hl=es

ResearchGate: https://www.researchgate.net/profile/Mireia Montana Blasco

Scopus ID: https://www.scopus.com/authid/detail.uri?authorId=56069911200

Academia.edu: https://uoc.academia.edu/MireiaMontana

\section{Candela Ollé Castellà}

Doctora en Documentación, profesora agregada AQU, 2 sexennios, 1 docentia. Su actividad de I+D+i (miembro de CSO2008-05525-C02-01/SOCI; CSO2011-29503; CSO2014-52830-P; RTI2018094360-B-I00) se centra en el acceso abierto, la ciencia abierta y la comunicación científica. Ha sido miembro de la red de excelencia Maredata (CSO2015-71867-REDT). Vinculada a la Universitat de Barcelona del 2006 al 2009 con una beca APIF para la realización del doctorado. En el 2009 se incorpora como profesora la Universidad Oberta de Catalunya. Des del 2017 es directora del Máster Universitario de Periodismo y Comunicación Digital: Datos y Nuevas Narrativas. Colaboradora del Grupo de investigación en Aprendizajes, medios de comunicación y entretenimiento (GAME) de la Universitat Oberta de Catalunya y miembro del grupo Cultura y Contenidos Digitales de la Universitat de Barcelona.

collec@uoc.edu

\section{Índice H: 11}

Orcid ID: https://orcid.org/0000-0002-8302-4790

Google Scholar: https://scholar.google.com/citations?user=rPVgYbEAAAAJ\&hl=es

ResearchGate: https://www.researchgate.net/profile/Candela_Olle_Castella

Scopus ID: https://www.scopus.com/authid/detail.uri?authorId=24477729000

Academia.edu: https://uoc.academia.edu/candelaolle

\section{Montse Lavilla Raso}

Doctora en Publicidad y RRPP. Compagina su actividad como Directora de Transformación Digital, en la agencia Arena Media del grupo Havas, con la docencia en diversas universidades. Con más de 20 años de experiencia en Marketing y Comunicación, ha trabajado como directora de marketing de Fotocasa y Habitaclia, entre otros portales de Adevinta. En la actualidad, es profesora colaboradora en la Universitat Oberta de Catalunya, en la Universitat Autònoma de Barcelona, en la Universitat Pompeu Fabra y colabora en Elisava. También es conferenciante en el ámbito de la transformación digital. Autora de diversos libros y publicaciones, fue galardonada con el premio Leadership Award a la mejor profesional del año en el marco del World Marketing Festival 2018.

mlavilla@uoc.edu

Orcid ID: https://orcid.org/0000-0002-8916-7872 